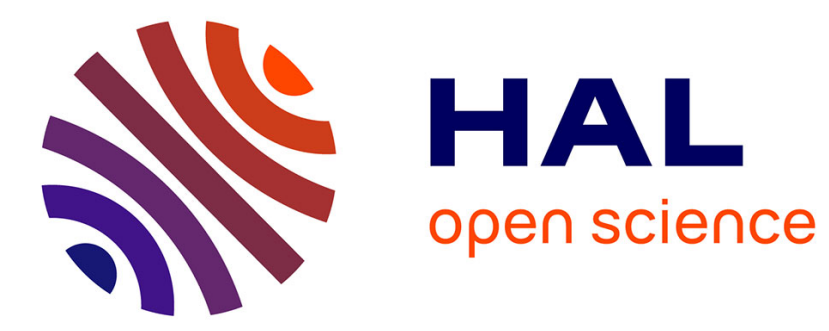

\title{
Profiles of recombination and transport parameters in thin sos films
}

\author{
S. Cristoloveanu, A. Chovet, G. Kamarinos
}

\section{To cite this version:}

S. Cristoloveanu, A. Chovet, G. Kamarinos. Profiles of recombination and transport parameters in thin sos films. Revue de Physique Appliquée, 1978, 13 (12), pp.615-618. 10.1051/rphysap:019780013012061500 . jpa-00244512

\section{HAL Id: jpa-00244512 https://hal.science/jpa-00244512}

Submitted on 1 Jan 1978

HAL is a multi-disciplinary open access archive for the deposit and dissemination of scientific research documents, whether they are published or not. The documents may come from teaching and research institutions in France or abroad, or from public or private research centers.
L'archive ouverte pluridisciplinaire HAL, est destinée au dépôt et à la diffusion de documents scientifiques de niveau recherche, publiés ou non, émanant des établissements d'enseignement et de recherche français ou étrangers, des laboratoires publics ou privés. 


\title{
PROFILES OF RECOMBINATION AND TRANSPORT PARAMETERS IN THIN SOS FILMS
}

\author{
S. CRISTOLOVEANU, A. CHOVET and G. KAMARINOS
}

Institut National Polytechnique de Grenoble

Laboratoire (*) «Physique des Composants à Semi-Conducteurs",

E.N.S.E.R.G., 23, av. des Martyrs, 38031 Grenoble Cedex, France

\begin{abstract}
Résumé. - Les propriétés des films Silicium Sur Isolant sont étudiées par des effets galvanomagnétiques où prédominent soit les phénomènes de recombinaison soit ceux de transport.

L'effet magnétodiode permet d'obtenir les vitesses de recombinaison en surface ainsi que le profil de la durée de vie volumique des porteurs : ainsi la décroissance de la durée de vie des porteurs d'un facteur de l'ordre de 10 près du Saphir permet de rendre compte de la valeur modérée obtenue pour la vitesse de recombinaison à l'interface Si-Saphir $\left(s \sim 20\right.$ à $\left.30 \mathrm{~ms}^{-1}\right)$.

Les mesures Hall sont utilisées pour étudier, en plus des mobilités volumiques moyennes, certaines inhomogénéités de transport; un modèle de décroissance linéaire de la mobilité avec la distance à l'interface $\mathrm{Si} / \mathrm{SiO}_{2}$ donnerait au voisinage de cet interface une valeur relativement grande pour la mobilité des électrons $\left(\left|\mu_{n}\right| \rightarrow 0,1 \mathrm{~m}^{2} \mathrm{~V}^{-1} \mathrm{~s}^{-1}\right)$.
\end{abstract}

Abstract. - SOS film properties are investigated by galvanomagnetic effects which are dominated by either recombination or transport phenomena.

The magnetodiode effect allows to obtain both the surface recombination velocities and the bulk lifetime profile : the decrease of the carrier bulk lifetime by an order of magnitude near the Sapphire accounts for the relatively moderate recombination velocity obtained at the Si/Sapphire interface $\left(s \sim 20\right.$ to $\left.30 \mathrm{~ms}^{-1}\right)$.

Bulk Hall measurements are used, besides the determination of mean drift and Hall mobilities, to study the transport inhomogeneities; a linear decrease of the mobility with the distance from the $\mathrm{Si} / \mathrm{SiO}_{2}$ interface would lead to a relatively large electron mobility near this interface $\left(\left|\mu_{n}\right| \rightarrow 0.1 \mathrm{~m}^{2} \mathrm{~V}^{-1} \mathrm{~s}^{-1}\right)$.

1. Introduction. - The order of magnitude of Silicon-On-Sapphire (SOS) film parameters related to recombination and transport phenomena, which are fundamental in SOS microcircuit performances can be obtained by several methods $[1,2]$. Some experimental results gave evidence for non homogeneities of the carrier bulk lifetime and mobilities $[3,4,5]$ because of the highly disturbed region near the Si-Sapphire interface $[6,7,8,9]$.

However, the exact picture of involved physical processes is difficult to get. In this paper, we attempt to give a more precise description of transport and recombination (bulk and surface) phenomena by fitting theoretical models with experimental results from galvanomagnetic properties of large resistive or injecting (magnetodiodes) SOS structures $\left({ }^{1}\right)$.

2. Study of recombination parameters from the SOS magnetodiode properties. - 2.1 PRINCIPLE. - The magnetodiode effect [10] appears when a double injecting device is placed in a magnetic field which gives rise to the magnetoconcentration effect [11]. Each

(*) ERA au CNRS no 659.

(') Supplied by LETI, CEN Grenoble. of these phenomena being essentially governed by carrier recombination, the magnetodiode effect is then a precious tool for recombination parameter investigations $[12,13]$.

It must be noted that when studying the properties of a long $p^{+} n n^{+}$(or $p^{+} p n^{+}$) SOS structure (Fig. 1) submitted to electric $E_{x}$ and magnetic $B_{z}$ fields, a two dimensional analysis is necessary to take into account both the longitudinal double injection (along $\mathbf{x}$ direction) and the transverse deflection of the injected plasma (along $\mathbf{y}$ direction, which is also the growth direction of the film). We recently outlined such a

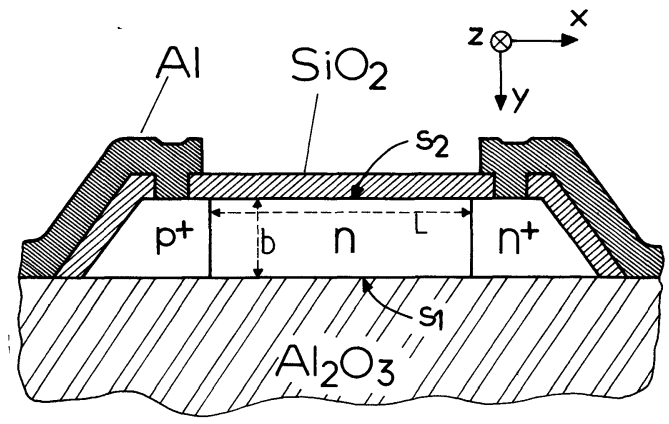

FIG. 1. - A n-Silicon-On-Sapphire magnetodiode ; $b=$ thickness, $L=$ length, $s_{1}, s_{2}=$ surface recombination velocities. 
theory [14], where Schockley-Read-Hall bulk and surface recombination laws can be used, as well as a non-uniform distribution of recombination centers along the $\mathbf{y}$ direction.

The current voltage characteristic $I\left(V=V_{x}\right)$ can then be written under the classical form for double injection phenomena :

$I=\left\langle I_{x}(y)\right\rangle=\frac{9}{8} e \mu_{p}\left|\mu_{n}\right|\left|n_{0}-p_{0}\right| \cdot \tau_{\text {eff }} \cdot \frac{V^{2}}{L^{3}} ;$

here $\tau_{\text {eff }}$ is an effective lifetime which can be expressed as a function of the bulk lifetime $\tau_{\mathbf{v}}(y)$, the surface $(y \pm b / 2)$ recombination velocities $s_{1}, s_{2}$ and the applied fields $E_{x}, B_{z}$ [14].

Experimental $I(V)$ curves (see Fig. 2) fitted with the analytical equation (1), lead to the best estimations for $s_{1}, s_{2}$ and $\tau_{\mathrm{v}}(y)$ profiles.

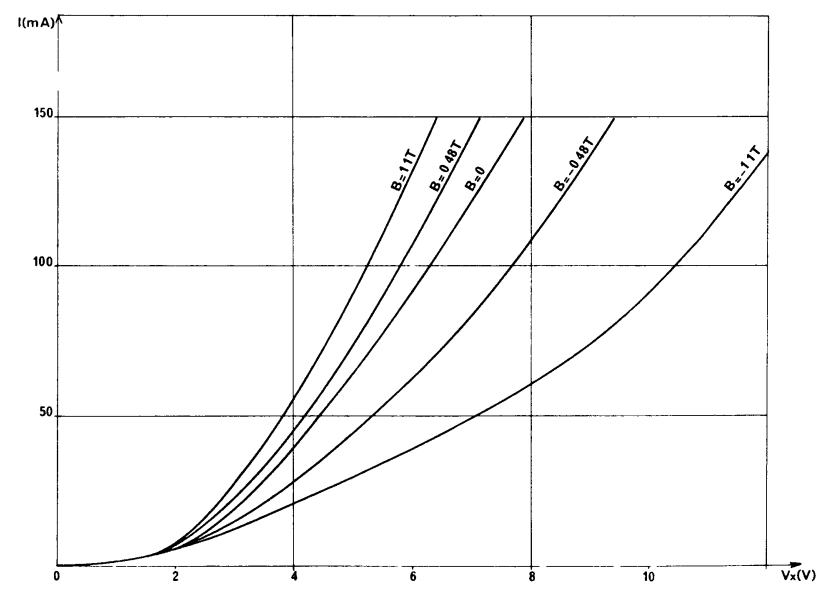

FIG. 2. - Typical current voltage characteristics of a SOS magnetodiode ; $b=7 \mu \mathrm{m}, n_{0} \simeq 10^{21} \mathrm{~m}^{-3}, L=18 \mu \mathrm{m}$.

2.2 MODEL OF HOMOGENEOUS RECOMBINATION CENTER DISTRIBUTION. - Such an hypothesis may be justified in the case of thick films. For example, with the thick magnetodiode of figure 2, we can get (with linear recombination laws) [12] :

$$
\begin{gathered}
\tau_{\mathrm{v}} \simeq 10 \mathrm{~ns} ; \quad s_{1}\left(\mathrm{Si} / \mathrm{Al}_{2} \mathrm{O}_{3}\right) \simeq 180 \mathrm{~ms}^{-1} ; \\
s_{2}\left(\mathrm{Si} / \mathrm{SiO}_{2}\right)<15 \mathrm{~ms}^{-1} .
\end{gathered}
$$

Since SRH recombination laws cannot modify the order of magnitude of these results, one must essentially keep in mind the bulk lifetime magnitude and an apparently high asymmetry in the interface recombination properties.

But in thin films $(b<1 \mu \mathrm{m})$, the hypothesis of homogeneity is no longer suitable; then transport or recombination parameters must be considered as averaged values, as long as their profiles are unknown.

2.3 MODEL OF NON UNIFORM RECOMBINATION CENTER (OR BULK LIFETIME) DISTRIBUTION. - On thin SOS films, the experimental results cannot be well fitted by models using a uniform bulk lifetime. It is why non uniform models must be tested.

For the sake of the best precision, we have used SRH non linear recombination laws because, in a magnetodiode, the injected carrier density is generally much higher than the equilibrium density. Injection conditions also enable us to suppose that doping or mobility inhomogeneities are less important here than lifetime inhomogeneity.

Last results of SIMS analysis [8] or noise measurements in strong depletion regime on MOS-SOS structures [9] give evidence for a highly disturbed region in the first $\sim 500 \AA$ near the sapphire interface. We have tested such a model (with higher recombination center density near the sapphire) for a thin $(0.6 \mu \mathrm{m}) p$ magnetodiode; a very good fit with the experiments is obtained with the following parameters :

a) The bulk lifetime near the sapphire is 10 to 20 times lower than elsewhere in the film (see in figure 3 the equilibrium bulk lifetime profile $\tau_{\mathrm{vo}}(y)$ which would be obtained without injection); so the discontinuity in the recombination center density cannot be higher than one order of magnitude (at least under double injection regime).

b) Equilibrium surface recombination velocities are found to be :

$$
\begin{aligned}
& \text { Si-Sapphire }:\left(s_{1}\right)_{0} \simeq 20 \text { to } 30 \mathrm{~ms}^{-1} \\
& \mathrm{Si}-S i O_{2}:\left(s_{2}\right)_{0} \simeq 0.1 \text { to } 10 \mathrm{~ms}^{-1} .
\end{aligned}
$$

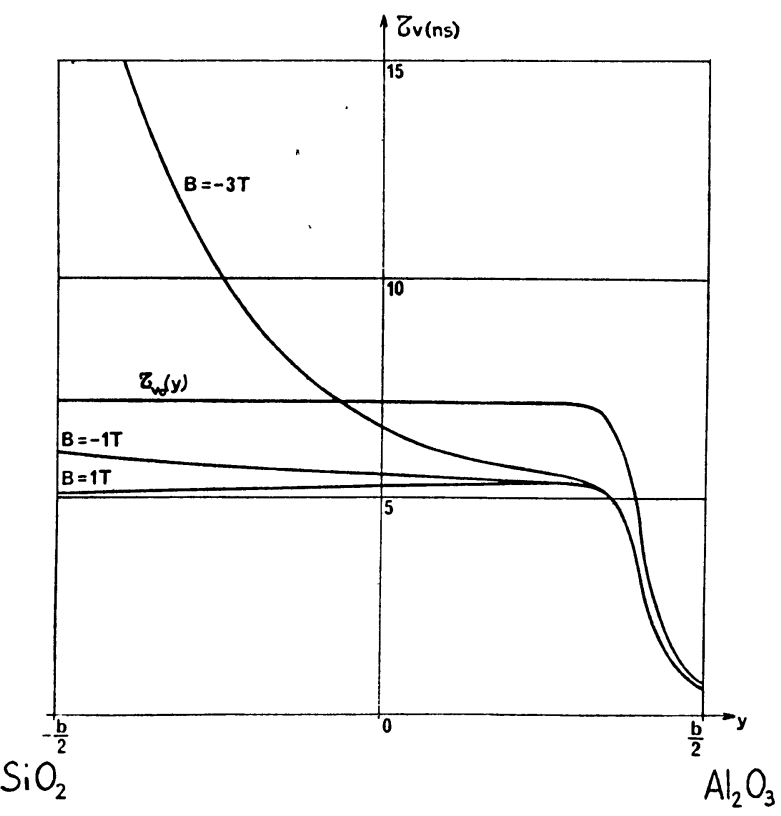

Fig. 3. - Bulk lifetime profile as deduced from fitting with experimental $I(V)$ curves for a thin magnetodiode $(b=0.6 \mu \mathrm{m})$; - Equilibrium bulk lifetime profile : $\tau_{\mathrm{vo}}(y)$; equilibrium surface recombination velocities :

sapphire $\left(s_{1}\right)_{0}=20 \mathrm{~ms}^{-1}$

$\mathrm{SiO}_{2} \quad\left(s_{2}\right)_{0}=1 \mathrm{~ms}^{-1}$

- $\tau_{\mathrm{v}}(y)$ : lifetime profiles under several injection conditions, due to different magnetic inductions $B$ and SRH recombination laws. 
Then the most important results concerning the recombination properties can be summarised as follows :

- The bulk lifetime is ten times lower in the 500$1000 \AA$ near the sapphire ;

- On the other hand, the Si/Sapphire interface is not very bad from the recombination point of view, the $s_{1}$ value being moderate; this is not due to the model used but can be found as soon as non uniform recombination center distributions are considered (see [14]).

This means that with homogeneous models the high recombination velocity at the Si/Sapphire interface accounts for the lower lifetime near the Sapphire interface;

- When comparing bulk and surface recombination rates a perfect continuity is obtained at a distance $t \simeq 150 \AA\left(t=s_{1} \tau_{\mathrm{vo}}\right) . t$ (which is a kind of characteristic thickness of the surface) can be interpreted, for the recombination aspect, as the depth of the surface influence inside the bulk. It is to note that, for the above homogeneous model ( $\$ 2.2), t$ is larger than $b$, which means that the sapphire interface is largely prevailing on the whole sample for the recombination rates.

We have thus precised the lifetime profile and the recombination properties in SOS films with the help of the magnetodiode effect (especially sensitive to recombination phenomena). Thereafter we shall give informations about transport parameter inhomogeneities obtained by more classical galvanomagnetic effects (in particular the Hall effect) which are independent of recombination properties.

3. Mobility profiles. - 3.1 EXPERIMENTAL RESUlTS. - In figure 4 is shown the Hall n-SOS structure used for the measurements of drift and Hall bulk mobilities ; for this purpose the device is not provided with the metallic gate already used to control the conducting channel in the film $[3,15]$.

Experiments have been performed at room temperature in a wide range of magnetic inductions $(0 \leqslant B \leqslant 12 \mathrm{~T})\left({ }^{2}\right)$; structures are operated under

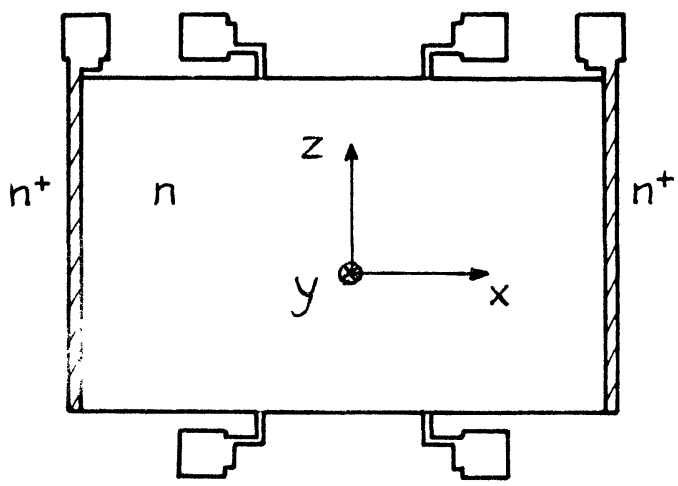

FIG. 4. - SOS device for Hall and magnetoresistance measurements (thickness $b=0.65 \mu \mathrm{m}$; length $L=1200 \mu \mathrm{m}$; width $=800 \mu \mathrm{m})$.

(2) The Service National des Champs Intenses, rue des Martyrs, Grenoble, is acknowledged for its cordial co-operation. low longitudinal currents in order to avoid the effects of $n^{+} n$ contact homojunctions [16, 17].

The experimental dispersion on Hall voltage measurements (Fig. 5) for several devices from the same wafer is less than $20 \%$. These results must be corrected for small magnetic inductions [18] by a coefficient $k \simeq 4 / 3$, owing to the shorting effect (reduction of the Hall field $E_{z}$, in the case of small length to width ratio, by the end contact short-circuits). The overlinearity in $V_{z}(B)$ for increasing induction $(B \geqslant 5 \mathrm{~T})$ is essentially due to the shorting effect attenuation [18].

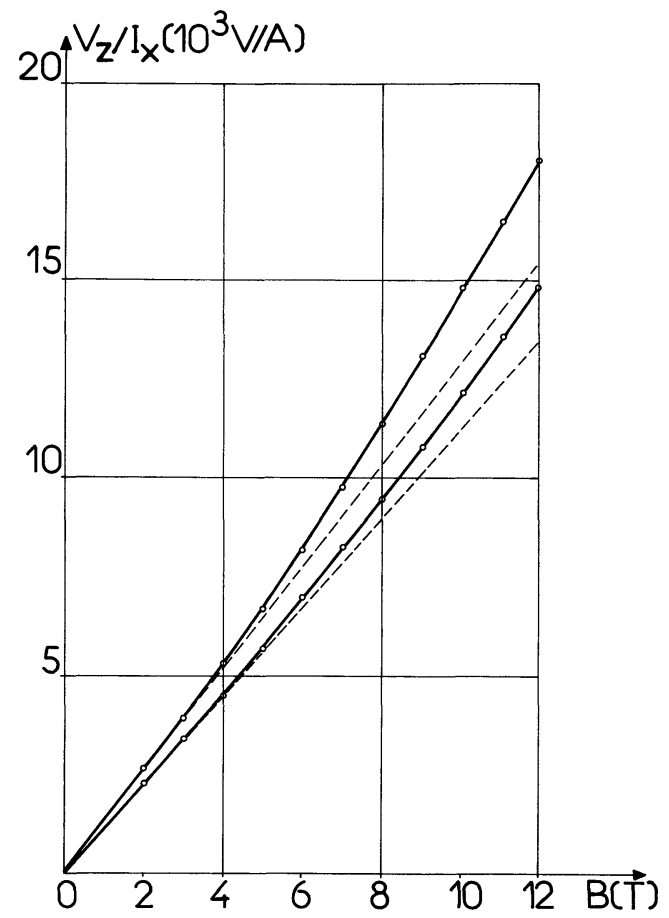

FIG. 5. - Hall voltage $V_{z} v s$. magnetic induction $B$; the two full curves show the extreme experimental characteristics; the dashed lines give the linear variation following the slope for low inductions (SOS conductivity $\left\langle\sigma_{x}\right\rangle \simeq 62.5 \div 69.3 \Omega^{-1} \mathrm{~m}^{-1}$ ).

From Hall and conductivity measurements, the mean doping as well as the mean drift and Hall mobilities are easily obtained :

$$
\begin{aligned}
\langle n\rangle & \simeq 7.4 \div 6.4 \times 10^{21} \mathrm{~m}^{-3} \\
\left\langle\left|\mu_{n}\right|\right\rangle & \simeq 0.053 \div 0.068 \mathrm{~m}^{2} \mathrm{~V}^{-1} \mathrm{~s}^{-1} \\
\left\langle\left|\mu_{\mathrm{H} n}\right|\right\rangle & \simeq 0.062 \div 0.08 \mathrm{~m}^{2} \mathrm{~V}^{-1} \mathrm{~s}^{-1}
\end{aligned}
$$

These mean values would be the real ones only if the film was homogeneous along $\mathbf{y}$ (or inhomogeneous over only a few hundred Å near the Sapphire interface).

3.2 THEORY AND DISCUSSION OF MOBILITY INHOMOGENEITY. - A more rigorous calculation of the Hall and magnetoresistance effects in inhomogeneous films is possible from the electron current equation :

$$
\mathbf{J}_{n}(y)=\mathbf{J}_{0}(y)+\mu_{\mathbf{H}} \mathbf{J}_{0} \wedge \mathbf{B}
$$


with

$$
\mathbf{J}_{0}(y)=\sigma(y) \mathbf{E}-q D(y) . \nabla n
$$

(here carrier mobilities, functions of $B$, are calculated by the Boltzmann formalism).

Notice that (without shorting effect) $E_{z}$ is only a function of $y$ coordinate and then $E_{x}, E_{z}$ are constant (to satisfy the steady state Maxwell equation $\boldsymbol{\nabla} \wedge \mathbf{E}=\mathbf{0}$ ). In inhomogeneous films the total (or mean) transverse current $\left\langle J_{z}(y)\right\rangle$ is null and the open-circuit Hall field will be expressed by averaged values along $\mathbf{y}$. In order to compare with the homogeneous case, effective Hall mobility $\mu_{\mathrm{H}}^{*}$ and Hall coefficient $R_{\mathrm{H}}^{*}$ are defined by :

$$
\begin{aligned}
\mu_{\mathrm{H}}^{*} & =-\frac{E_{z}}{B E_{x}}=\frac{\left\langle\mu_{\mathrm{H}} \sigma\right\rangle}{\langle\sigma\rangle} \\
R_{\mathbf{H}}^{*} & =-\frac{E_{z}}{B\left\langle J_{x}(y)\right\rangle}=\frac{\left\langle\mu_{\mathrm{H}} \sigma\right\rangle}{\left\langle\sigma^{2}\right\rangle\left(1+\left(\mu_{\mathrm{H}} B\right)^{2}\right)} .
\end{aligned}
$$

One of the simplest models (proposed for the $M O S$ mobility variation in SOS films $[3,15])$ is a linear decrease of carrier mobility with distance from the $\mathrm{SiO}_{2}$ interface. If we are testing a decrease towards a very low mobility in the $600-700 \AA$ near the sapphire, we can consider that the doping variation is comparatively small. In weak magnetic inductions, where $\mu, \mu_{\mathrm{H}}$ don't depend on $B$, and where

$$
\mu_{\mathbf{H}}(y)=\frac{3 \pi}{8} \mu(y)
$$

the effective Hall mobility becomes :

$$
\mu_{\mathrm{H}}^{*}=\frac{3 \pi}{8} \frac{\left\langle\mu^{2}\right\rangle}{\langle\mu\rangle} .
$$

Resulting drift and Hall mobility spatial distribution are plotted in figure 6.

From this model it is clear that, in SOS films, the drift electron mobility at $\mathrm{Si} / \mathrm{SiO}_{2}$ interface could (nearly) approach the values measured on other thin silicon films.

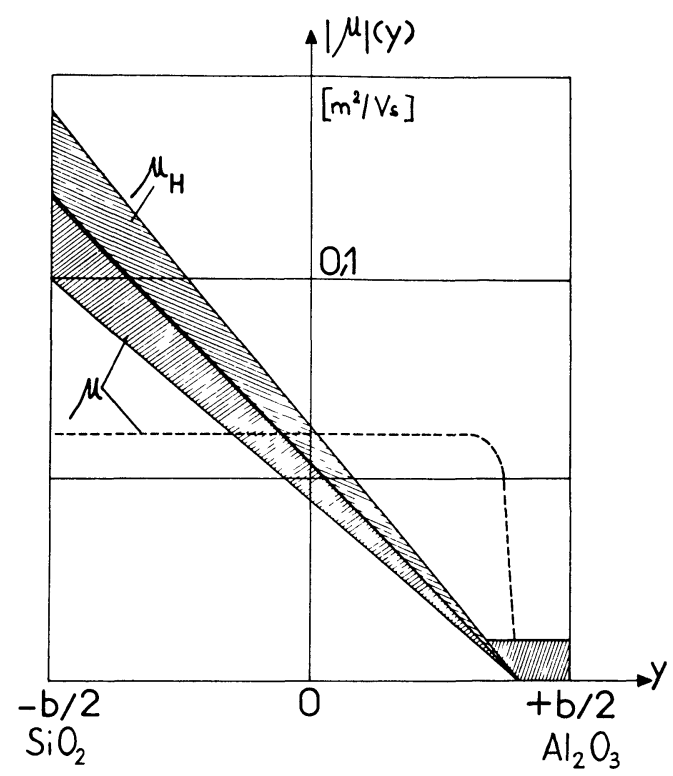

FIG. 6. - Linear variation of drift and Hall mobilities in thin SOS films $(b=0.65 \mu \mathrm{m})$. For comparison the dashed line shows a near-homogeneous profile.

Such mobility modelling will be improved by analysing films with different thicknesses. Moreover the high value of the longitudinal magnetoresistance with regard to the transverse magnetoresistance leads us to suspect important anisotropy effects.

4. Conclusion. - Recombination properties in SOS films have been analysed by an original magnetosensitive method based on the magnetodiode effect, which is the only one allowing a simultaneous study of recombination both in the bulk and at the two interfaces. Besides the bulk lifetime profile, the important result is the moderate recombination rate at the Si-Sapphire interface. The non-uniformity of mobility is studied by means of bulk Hall experiments ; in particular, it seems that the surface region near $\mathrm{SiO}_{2}$ could have transport properties not too much altered by the sapphire proximity.

\section{References}

[1] Preuss, E., Invited Paper, Fall Meeting of the Electroch. Soc., Las Vegas (1976).

[2] Schlötterer, H., Preuss, E., Invited Paper, 7th ESSDERC Brighton (1977), Solid State Devices, Inst. Phys. Conf. Ser. No 40, London (1978) pp. 8-31.

[3] IpRI, A. C., J. Appl. Phys. 43 (1972) 2770.

[4] Hsu, S. T., ScotT, J. H., RCA Review 36 (1975) 240.

[5] McGreivy, D. J., Viswanathan, C. R., Appl. Phys. Lett. 25 (1974) 505.

[6] Picraux, S. T., Thomas, G. J., J. Appl. Phys. 44 (1973) 594.

[7] Abrahams, M. S., Buiocchi, C. J., Corboy, J. F., Cullen, G. W., Appl. Phys. Lett. 28 (1976) 275.

[8] Trilhe, J., Blanchard, B., Borel, J., Proc. 3rd Int. Conf. Solid Surfaces, Vienna (Austria) (1977) 541.

[9] Gentil, P., Chausse, S., Solid State Electron. 20 (1977) 935.

[10] Pfleiderer, H., Solid State Electron. 15 (1972) 335.

[11] Chovet, A., Kamarinos, G., Revue Phys. Appl. 6 (1971) 345.

[12] Cristoloveanu, S., Kamarinos, G., Viktorovitch, P., Borel,
J., Staderini, R., Proc. 3rd Int. Conf. Solid Surfaces, Vienna (Austria) 1977, 1943

[13] Lilienkamp, P., Pfleiderer, H., Phys. Status Solidi (a) 43 (1977) 479

[14] Cristoloveanu, S., Chovet, A., Kamarinos, G., to be published in Solid State Electron. (Proc. Int. Conf. on Recombination in Semiconductors, Southampton, Aug.Sept. 1978).

[15] Elliot, A. B. M., ANDerson, J. C., Solid State Electron. 15 (1972) 531.

[16] Scharfetter, D. L., Lade, R. W., Jordan, A. G., IEEE Trans. Electron. Devices ED 10 (1963) 35.

[17] Lade, R. W., JoRdan, A. G., IEEE Trans. Electron. Devices ED 10 (1963) 268.

[18] BeER, A. C., Galvanomagnetic effects in Semiconductors, Sol. St. Phys., Suppl. 4 (Academic Press, New York) 1963, 57. 